\title{
ON THE ANODIC PASSIVITY OF IRON IN MOLTEN POTASSIUM BISULPHATE*
}

\author{
R. G. Casino, J. J. Podestá and A. J. Arvia \\ Instituto Superior de Investigaciones, División Electroquímica, Facultad de Ciencias \\ Exactas, Universidad Nacional de la Plata, La Plata, Argentina
}

\begin{abstract}
The electrochemical behaviour of pure iron anodes in molten $\mathrm{KHSO}_{4}$ at $250^{\circ} \mathrm{C}$ was studied. Typical passivity phenomena were observed under potentiostatic as well as galvanostatic runs. A transition time related to the onset of full passivity was determined. The passive film was studied by $\mathrm{X}$-ray diffraction. Its average structure corresponded to $\mathrm{Fe}_{\mathbf{3}} \mathrm{O}_{\mathbf{4}}$.

The mechanisms of passivation and corrosion of passive iron are discussed on the basis of behaviour of passive iron in aqueous systems.

Résumé-Le comportement électrochimique des anodes de fer pur dans du $\mathrm{KHSO}_{4}$ à $250^{\circ} \mathrm{C}$ a été étudié. Des phénomènes de passivité furent étudies avec des techniques potentiostatiques et galvanostatiques. On a obtenu un temps de transition galvanostatique qui correspond a l'électrode de fer totalement passivé. La structure de la couche passive a été étudiée par diffraction de rayons $\mathrm{X}$. La structure moyenne est exprimée comme $\mathrm{Fe}_{3} \mathrm{O}_{4}$.

On discute le mécanisme de passivation et corrosion du fer passif sur la base du comportement du fer passif dans les systèmes aqueux.
\end{abstract}

Zusammenfassung - Es wurde das elektrochemische Verhalten der Reineisenanoden in geschmolzenem KHSO, bei $250^{\circ} \mathrm{C}$ untersucht. Die typischen Passivitätsphänomene wurden unter potentiostatischen und galvanostatichen Bedingungen gemessen. Es wurde eine Ubergangszeit gefunden, welche dem Beginn der vollen Passivität entspricht. Die Struktur des passiven Films wurde röntgenographisch bestimmt. Die durchschnittliche Struktur entspricht dem $\mathrm{Fe}_{3} \mathrm{O}_{4}$.

Passivitäts- und Korrosionsmechanismus werden auf den Basis des Verhaltens von passiven Eisen in wässerigen Systemen diskutiert.

\section{INTRODUCTION}

METAL corrosion and passivity in molten salts have been little studied in comparison with those in ionic aqueous solutions or high temperature gas systems. Most of the published data refer either to empirical tests under particular conditions or to the establishment of a quasi-equilibrium potential of the metal and potential/pO ${ }^{2-}$ diagrams. A survey of these researches and the special features distinguishing corrosion in molten salts has been published recently.,2 The behaviour of metals in fused salts from the metallographic standpoint has been also studied. Thus, the corrosion of iron in melts, such as molten chlorides, sulphates and mixtures of chlorides and sulphates and chlorides and nitrates, have been investigated. ${ }^{3-7}$

Since corrosion and passivity are not completely independent electrochemical processes, it was considered of interest to determine the behaviour of iron electrodes as anodes in molten potassium bisulphate. For this system, only a study of its rest potential has been reported. ${ }^{8}$

As the behaviour of these electrodes in aqueous solutions is known, comparison between these systems can be attempted. Water plays a very important mechanistic role both in the anodic dissolution as well as in the passivation of iron in aqueous solutions, and its absence reflects in a different kinetic behaviour of iron dissolution and passivity in the ionic melts.

* Manuscript received 20 August 1969. 


\section{EXPERIMENTAL TECHNIQUE}

The electrolysis cell was made of Pyrex glass following already described designs.9 Potassium bisulphate from Mallinckrodt, p.a., was used.

The iron electrodes were prepared from iron wires from Light and Co. with a purity of $99.998 \%$. The structure of the iron electrodes at $250^{\circ} \mathrm{C}$ was $\alpha-\mathrm{Fe}$. The iron electrodes were electropolished before use, with $10 \%$ perchloric acid solution in butyl cellosolve. Each electrode was made anode for $1 \mathrm{~min}$ at $10^{\circ} \mathrm{C}, 1.8 \mathrm{~A}$ and $14-15 \mathrm{~V}$, by employing in the cell a concentric stainless steel cathode. ${ }^{10}$ A hydrogen electrode in $\mathrm{KHSO}_{4}$ melt at $1 \mathrm{~atm}$ hydrogen pressure was used as reference electrode; ${ }^{9}$ all potentials quoted are referred to this electrode as zero.

Conventional circuitry was employed to obtain steady and non-steady results, either potentiostatically or galvanostatically as mentioned in earlier publications. ${ }^{11}$ Potentio-galvanostatic experiments were also made, employing the circuitry described elsewhere. ${ }^{12}$ The rest potential and the applied potential were read with a highimpedance input electronic voltmeter and the time dependence of the electrode potential was recorded photographically from the oscilloscope screen.

The surface compounds were analysed by $\mathrm{X}$-ray diffractometry with a Philips PW-1010 unit employing a molybdenum tube and a zirconium filter operated at $40 \mathrm{KW}$ and $20 \mathrm{~mA}$. These experiments were made with iron samples of $99.998 \%$ purity previously cool-machined between stainless steel plates to obtained flat electrodes of definite shape. These electrodes were kept under an argon atmosphere.

RESULTS

The current efficiency for iron dissolution was obtained in the region of potentials preceding the region of passivity. The amount of iron dissolved as $\mathrm{Fe}^{3+}$ at any potential corresponded to the maximum anodic current being, therefore, independent of the anodic potential.

Figures 1 and 2 show semilogarithmic plots of the potentiostatic current/voltage curves obtained with an electropolished iron electrode. The initial rest potential was between -0.8 and $-1 \cdot 0 \mathrm{~V}$. On applying a small anodic potential the cd increased from $10^{-6} \mathrm{~A} / \mathrm{cm}^{2}$ to a maximum value of about $2 \times 10^{-4} \mathrm{~A} / \mathrm{cm}^{2}$ which is a critical passivating $\mathrm{cd}$. In this potential range the cd is unstable, with a tendency to approach the maximum value. At more positive potentials the current decreases sharply to a low steady value. Thus, between $-0.6 \mathrm{~V}$ and $0.8 \mathrm{~V}$ a constant $\mathrm{cd}$ of about $10^{-6} \mathrm{~A} / \mathrm{cm}^{2}$ is observed. A passivation potential of the iron electrode can be defined corresponding to the onset of full passivity; at $250^{\circ} \mathrm{C}$, it is $-0.30 \pm 0.05 \mathrm{~V}$.

On increasing the potential beyond the region of passivity the cd increased again because of electrochemical oxidation processes on the passive iron electrode. These experiments were repeated starting from the region corresponding to the hydrogenevolution reaction as seen in Fig. 3 , and confirm that the most reliable value of the mixed potential of the iron electrode in molten potassium bisulphate referred to the saturated hydrogen electrode in the melt is $-1.0 \mathrm{~V}$, in agreement with the conclusion from cathodic experiments. ${ }^{13}$

Figure 4 shows a typical galvanostatic current/voltage curve. In the vicinity of the initial potential the current is practically independent from the applied potential. On increasing the cd beyond its maximum value a discontinuity in the cd/voltage curve was observed, as expected for a galvanostatic run involving electrode passivation. 


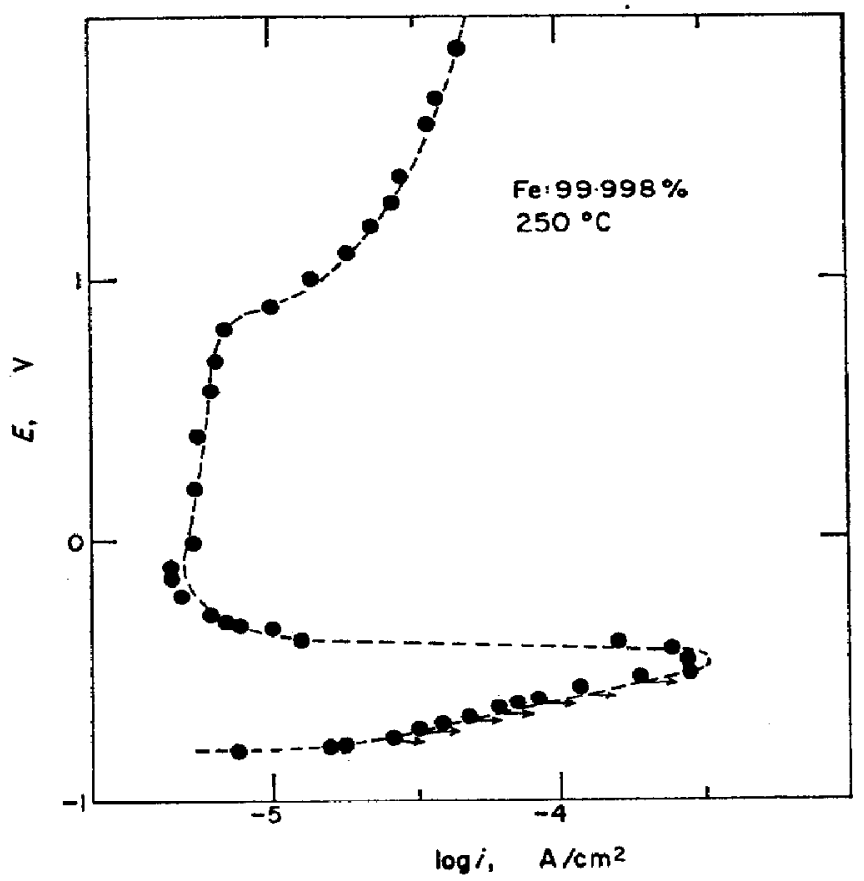

FIG. 1. Semilogarithmic plot of a potentiostatic cd/voltage curve.

Points between rest potential and passivity potential correspond to unstable current.

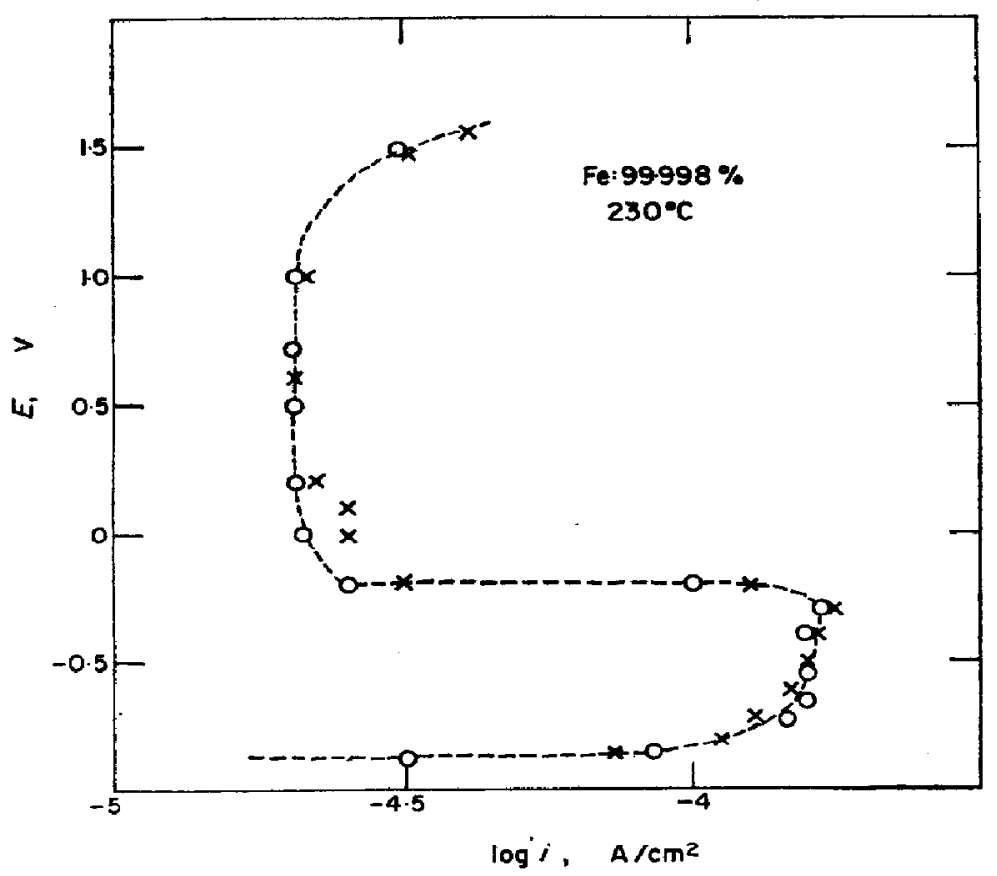

FIG, 2. Semilogarithmic plot of a potentiostatic cd/voltage curve. Each point was read after steady current was obtained. 


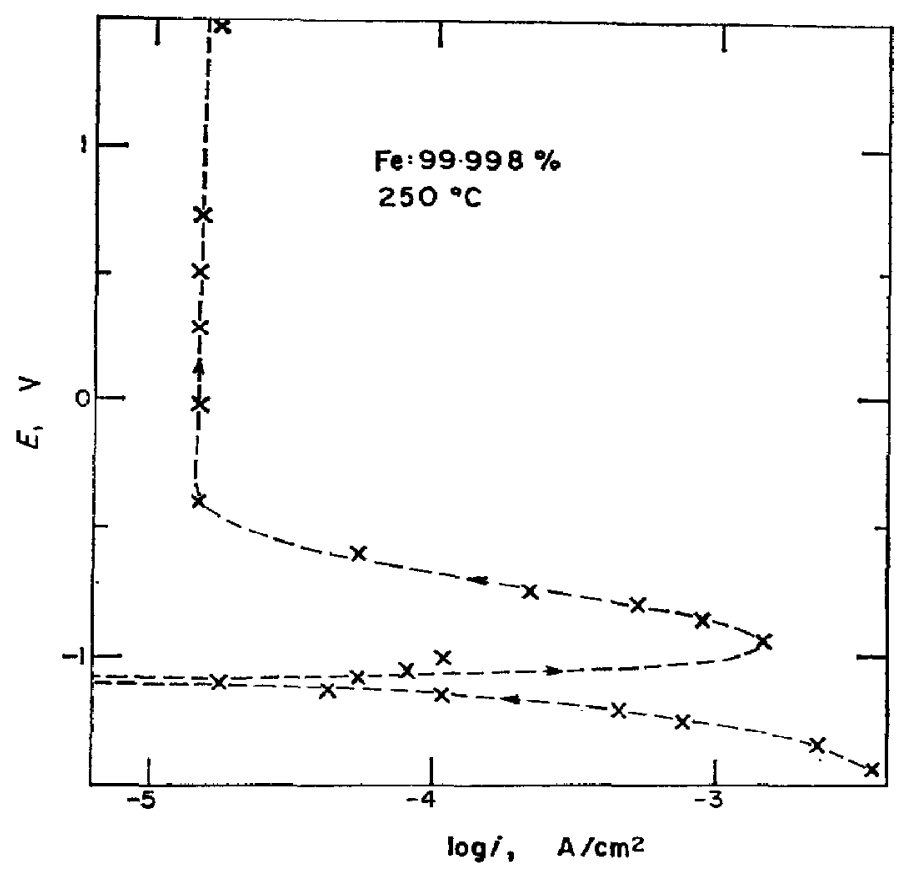

FIG. 3. Semilogarithmic plot of a potentiostatic cd/voltage curve. Starting from the cathodic region.

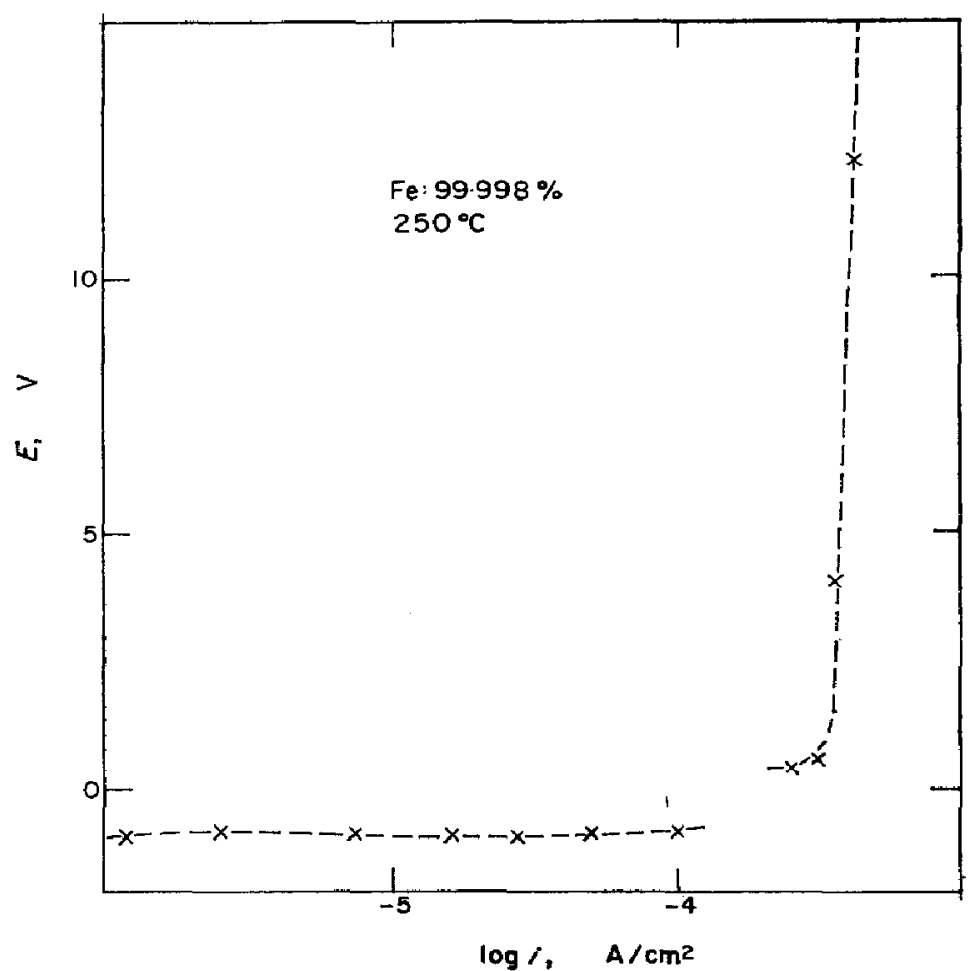

FIG. 4. Semilogarithmic plot of a galvanostatic cd/voltage curve. 
The passivity region is reached more definitely by running the experiments in the presence of oxygen gas. In this case the iron electrode approaches the passive region very rapidly. Electrolysing at high positive potentials for a long time at $250^{\circ} \mathrm{C}$, gave a visible amount of ferric oxide, which dissolved partially in the melt at higher temperature.

If build-up curves are obtained reaching the passive region a sharp transition time is observed, which is absent in the decay curve, as shown in Fig. 5. These results are coincident with those obtained under steady-state conditions.
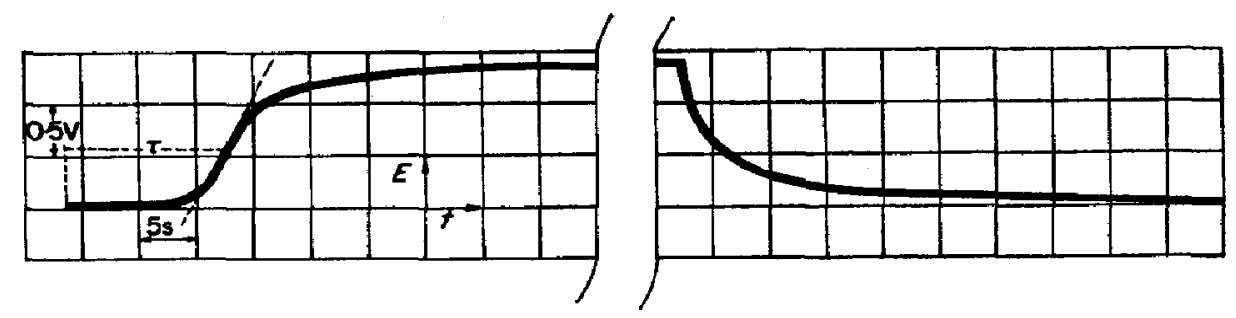

FIG. 5. Build-up and decay curves obtained in the passivity region.

Typical transition time is shown.

The potentio-galvanostatic experiments were performed at a cd corresponding to the passivity region. A passive film of predetermined thickness was potentiostatically built up and later dissolved by applying a galvanostatic current pulse in the reverse direction. As shown in Fig. 6, during the galvanostatic dissolution of the passive film

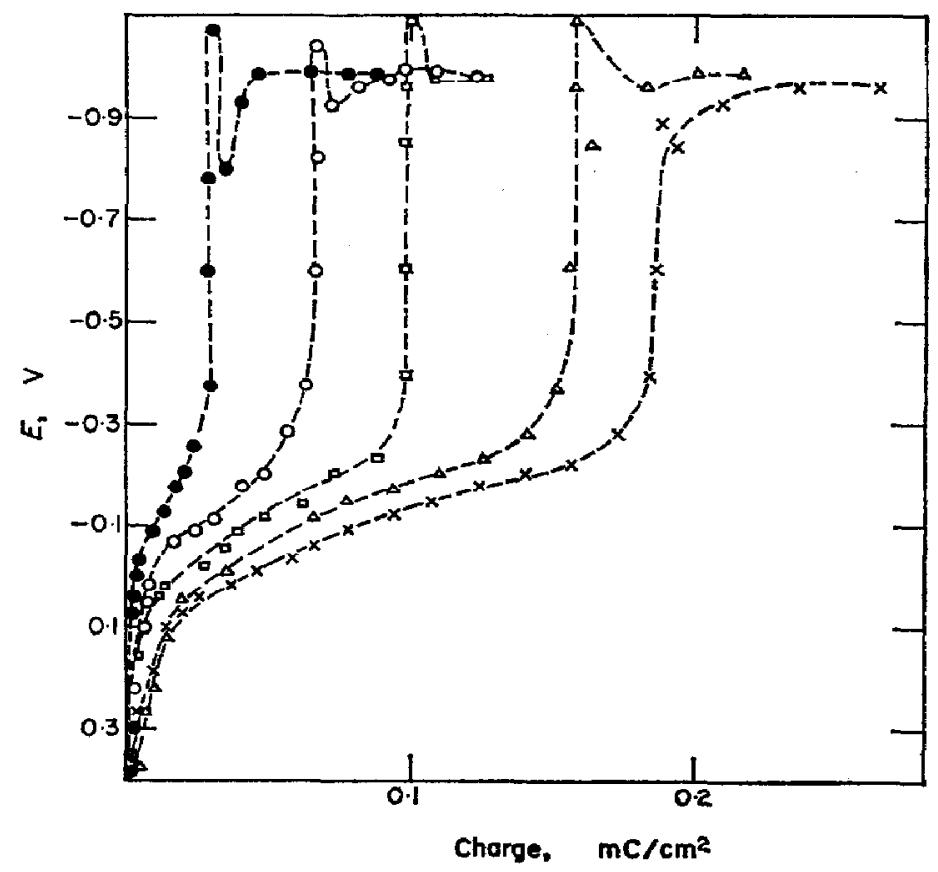

FIG. 6. Potential/charge plots obtained from potential-galvanostatic runs at different potentiostatic oxidation times.

$0,15 \mathrm{~s} ; 0,30 \mathrm{~s} ; \square, 60 \mathrm{~s} ; \Delta, 90 \mathrm{~s} ; \times, 120 \mathrm{~s}$. 
the electrode potential decayed from the initial voltage to a final value of about $-1.0 \mathrm{~V}$. The dissolution process is characterized by a transition time.

A linear relationship between the potentiostatic oxidation time and the galvanostatic transition time was established. However, this relationship indicated a contribution in the dissolution process of an additional amount of film, probably formed spontaneously on the iron electrode. The charge involved in the potentiostatic film formation was evaluated by integrating the corresponding current/time curve.

The time of the potentiostatic run was assumed to be proportional to the film thickness. If the potentio-galvanostatic experiments were performed starting with a surface already passivated, a different behaviour during the galvanostatic pulse was observed, as seen in Fig. 7. Thus, if the iron electrode was polarized potentiostatically

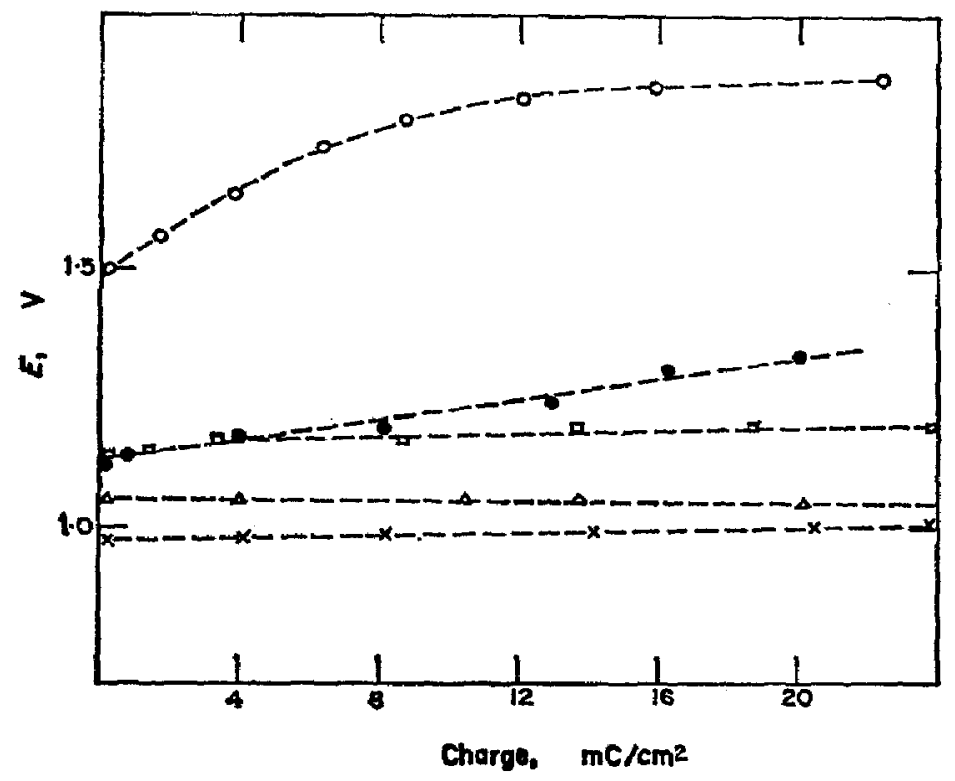

Fro. 7. Potential/charge plots obtained from potentio-galvanostatic runs at different potentiostatic oxidation times beyond the passivity region. $\triangle, 0.5 \mathrm{~h} ; 1.25 \mathrm{~h} ; \square, 5 \mathrm{~h} ; x, 6 \mathrm{~h} ; 0,8 \mathrm{~h}$.

at $1.1 \mathrm{~V}$ and later the galvanostatic pulse was applied, the potential reached a value close to $1.5 \mathrm{~V}$, which afterwards decayed slowly to more negative values, finally approaching the initial rest potential. The behaviour of the iron electrodes in these experiments changed with the duration of the potentiostatic pulses.

The nature of the film formed on the iron surface was examined by X-ray diffraction. The diffraction pattern exhibited the characteristic peaks of potassium bisulphate, $\alpha$-iron, and a mixture of iron oxides.

According to these results the oxide formed in the passive region apparently corresponds to a compound having the average composition $\mathrm{Fe}_{3} \mathrm{O}_{4}$. If the latter participates in the equilibrium $4 \mathrm{FeO} \rightleftharpoons \mathrm{Fe}_{3} \mathrm{O}_{4}+\mathrm{Fe}$, its formation is largely favoured in the range between 300 and $570^{\circ} \mathrm{C} .^{14}$

From the galvanostatic non-steady runs it was concluded that the charge related to film formation approaches a maximum value, indicating that a limiting thickness of 
the passive film is attained. Finally, it was also observed that under certain circumstances, in the vicinity of the passivity potential a periodic change of cd was observed, which resembled the change already described for iron electrodes in ionic aqueous media. ${ }^{15}$

\section{DISCUSSION}

After comparing these results with those obtained with iron electrodes in acid aqueous solutions, a difference appears in the region of low potential, but in the passivity region the iron electrode behaves apparently in an almost similar way in the aqueous media and in the bisulphate melt. In the low potential region the iron electrode in the acid aqueous media exhibits an active region characterized by a Tafel line of slope $2 R T / 3 F$. This has been assigned to a reaction mechanism where water, either through $\mathrm{H}^{+}$or $\mathrm{OH}^{-}$ions, plays an important role. ${ }^{16-21}$ No equivalent active region has been found with iron electrodes in the melt; the dissolution of the metal occurs initially with a maximum rate at any anodic potential close to initial rest potential. This result cannot be explained by any conventional reaction mechanism involving a charge-transfer step as rate-determining. A potential-independent process is involved in the reaction mechanism.

At potentials beyond the passivation potential there is a passive region where the cd is practically potential-independent over about $1 \mathrm{~V}$. This passivity cd represents a quasi-steady state process where the amount of iron oxide dissolving should be equal to that being formed. This slow corrosion of passive iron is analogous to that observed in aqueous acid media. ${ }^{22}$ This particular mode of dissolution of iron involves a complex chemical process whose rate depends mainly on the characteristics of the oxide-melt system. The final product is probably $\mathrm{Fe}^{3+}$ in the melt.

It is important to discuss the probable mechanism of film formation and structure of the passive film. The former must involve the migration of iron through the film, probably as $\mathrm{Fe}^{3+}$, from the metal/oxide interface to the oxide/melt interface. This process is provoked by the gradient of the potential field produced within the film. The porosity of the film formed as deduced from Figs. 1 and 2 seems to depend on the potential-sweeping rate. However, in the region of full passivity a non-porous film is apparently formed.

If the electrode potential in the passive region is determined by the oxygen gas pressure, according to Nernst's equation, the interpretation already given for the corrosion of passive iron in sulphuric acid solutions at $25^{\circ} \mathrm{C},{ }^{23-24}$ can be extended to molten potassium bisulphate. Thus, it can be assumed that the diffusion rate per unit apparent area to the oxide/melt interface is given by the simple diffusion equation

$$
\frac{\mathrm{d} n}{\mathrm{~d} t}=D \frac{\left(c_{1}-c_{2}\right)}{\delta}=F\left(c_{2}, p_{0_{2}}\right),
$$

where $c_{1}$ is the concentration of diffusing species at the metal/oxide interface, $c_{2}$ its concentration at the oxide/melt interface, $D$ its diffusion coefficient and $\delta$ the thickness of the oxide film. To reach the oxide/melt interface, the reacting species has to go through the passive film, in order to react with the oxygen present in the melt. The rate of passive iron corrosion depends upon the iron concentration at the oxide/melt interface and the oxygen concentration in the melt. Both concentrations are potential-dependent, but this is not the case for the corrosion process of passive iron. As 
the potential at the oxide/melt interface increases, the oxygen concentration increases. Consequently, the rate of corrosion increases and the iron concentration at the oxide/melt interface diminishes. Thus, at higher positive potentials the concentration gradient in the passive film increases and therefore in order to keep a constant rate of corrosion, at any potential within the region of full passivity, the ratio $\Delta c / \delta$, according to (1), must be constant.

The postulated mechanism for the dissolution of passive iron quite likely involves $\mathrm{Fe}^{3+}$ as the main entity playing a definite role in the diffusion process within the film. ${ }^{26-29}$ If a process of this type occurs it is reasonable to suppose that the passivating non-porous film is in a non-equilibrium state. Therefore, it is possible, in principle, to assume, in a thin passive film the composition on the metal/oxide approaches a $1: 1$ iron to oxygen ratio whereas at the oxide/melt interface it approaches the ratio $2: 3$. The composition of the film from one interface to the other probably changes monotonously so that the average structure of the film is represented as $\mathrm{Fe}_{3} \mathrm{O}_{4}$. As the passive film becomes thicker, then the $\mathrm{Fe}_{3} \mathrm{O}_{4}$ definitely predominates. The minimum thickness of the passive film in molten potassium bisulphate, at $250^{\circ} \mathrm{C}$, as deduced from the transition times rcad on the galvanostatic transients, is about $2 \AA$. For thinner films, approaching a monolayer, an appreciable charge transfer due to tunnel effect should participate in the mechanism of the corrosion process. Furthermore, that minimum passive thickness indicates a definite structure associated with the change from electronic conduction to ionic conduction within the passive film after reaching the passivation potential.

The present results indicate that the rate of growth of the passive film can be expressed, as in the case of aqueous sulphuric acid, by a rate equation derived from the theory of high field ionic conduction. ${ }^{30-34}$ If the growth of the solid oxide film is mainly due to the transport of cations to interstitial vacancies through consecutive energy barriers having their maxima decreasing in the direction of the applied field, the following simplified rate equation results,

$$
i=i_{0} \exp (\beta E)=i_{0} \exp \left(\frac{\beta \Delta \varphi}{\delta}\right)
$$

where $i_{0}$ and $\beta$ are constants, $E$ is the strength of the electrical field and $\Delta \varphi$ the potential difference across the oxide film of thickness $\delta$. According to (2), a constant current exists if the ratio $\Delta \varphi / \delta$ is kept constant, as discussed above.

Acknowledgements-The present work was in part supported with a Grant from S.E.N.I.D., Secretaria de Marina of Argentina. J. J. P. acted under a contract of the Facultad de Ingeniería, Departamento de Ingeniería Quimica, Universidad de La Plata, and R. G. C. participates with a fellowship from the Consejo Nacional de Investigaciones Científicas y Técnicas, of Argentina.

\section{REFERENCES}

1. H. Shimotake and J. C. Hesson, Adv. Chem. Ser., No. 64, p. 149, Am. Chem. Soc. (1967).

2. D. INMAN and N. S. WRENCH, Br. Corros, J. 1, 246 (1966).

3. V. P. Kochergin, A. V. Kabikov and O. N. SkORNYAKOVA, J. appl. Chem. USSR 27, 883 (1954).

4. V. P. Kochergin, L. G. Kharbullina and O. G. Potapova, Zh. neorgan. Khim. 1, 2617 (1956).

5. V. P. Kochergin and G. I. Stolyarova, J. appl. Chem. USSR 29, 789 (1956).

6. A. LA VeCCHIA and B. VICENTINI, Electrochim. Metall. 3, 198 (1968).

7. G. Bombara, G. Baudo and A. Tamba, Corros. Sci. 8, 393 (1968).

8. A. J. Arvia and H. A. Vidrla, Electrochim. Acta 11, 537 (1966).

9. A. J. Arvia, A. J. Calandra and H. A. Videla, Electrochim. Acta 10, 33 (1965). 
10. W. J. McTegart, The Electrolytic and Chemical Polishing of Metals. Pergamon Press, London (1956).

11. R. G. Casino, J. J. Podestá and A. J. Arvia, Anal. Asoc. Quim. Arg, in press.

12. N. SATo and T. NotoyA, J. electrochem. Soc. 114, 585 (1967).

13. R. G. Casino, J. J. Podestí and A. J. Arvia, Anal. Asoc. Quim. Arg., in press.

14. J. W. MeLloR, A Comprehensive Treatise on Inorganic and Theoretical Chemistry, Vol. XIV, Part 3. Longmans, London (1942).

15. U. F. Franck and R. Fritz-Hugh, $Z$. Elektrochem. 65, 156 (1961).

16. J. O'M. Bockris, D. Drazic and A. R. Despic, Electrochim. Acta 4, 325 (1961).

17. J. O'M. BockRIs and H. KITA, J. electrochem. Soc. 108, 676 (1961).

18. J. O'M. Bockris and D. DrazIC, Electrochim. Acta 7, 293 (1962).

19. J. J. PodestÁ and A. J. Arvia, Electrochim. Acta 10, 159 (1965).

20. J. J. Podrstá and A. J. ArviA, Electrochim. Acta 10, 171 (1965).

21. E. J. KeLLY, J. electrochem. Soc. 112, 124 (1965).

22. K. VetTer, Electrochemical Kinetics, p. 748. Academic Press, New York (1967).

23. U. F. Franck and K. Wer,, Ber. Bunsenges. phys. Chem. 56, 814 (1952).

24. K. G. WEIL, Z. Elektrochem. 59, 711 (1955).

25. K. J. VetTer, Ber. Bunsenges. phys. Chem. 55, 675 (1951).

26. W. Schwartz, Ber. Bunsenges. phys. Chem. 55, 180 (1951).

27. K. J. VeTTER, Ber. Bunsenges, phys. Chem. 56, 106 (1952).

28. K. F. BONHOEFFER and K. J. VETTER, Z. phys. Chem. 196, 142 (1950).

29. J. L. ORD and J. H. BARTLETt, J. electrochem. Soc. 112, 160 (1965).

30. J. Frenkel, Kinetic Theory of Liquids. Dover, New York (1955).

31. N. Cabrera and N. F. Motr, Rep. Prog. Phys. 12, 163 (1959).

32. E. VeRWeY, Physica 2, 1059 (1935).

33. K. F. BONHOEFFER, Ber. Bunsenges. phys. Chem. 52, 24 (1948).

34. P. W. Moshtev, Ber. Bunsenges. phys. Chem. 71, 1079 (1967). 